\title{
Great marquee for high-speed trains in the new railway station of Málaga
}

\author{
C. Jurado \\ Polytechnic University of Madrid, (Spain).
}

ABSTRACT: The commercial centre VIALIA and the new railway station of the AVE (high speed train) in Malaga was inaugurated in November 2006, just on the place of the former railway station. The new railway station with an investment of 134,7 million Euros occupies a surface of $51.377 \mathrm{~m}^{2}$, five times the surface of the former station. The enclosure is the biggest intermodal and commercial centre of Spain which comprises a parking of $21.000 \mathrm{~m}^{2}$ for 1300 parking places, one commercial area and a hotel with a total extension constructed of approximately $100.000 \mathrm{~m}^{2}$. The spaces of leisure contain cinemas, shops, restaurants, bowling, gymnasium, swimming pool and zones of passenger's traffic

\section{INTRODUCTION}

During the years 2001 and 2002 it was realized by the author of this paper, the project of the Commercial Centre VIALIA and railway station of AVE (high speed train) of Málaga, called María Zambrano station. The works have began at the middle of the year 2002 finishing on 2006.

The Commercial Centre VIALIA transformed the former railway station of Malaga on a modern station for high-speed trains, together with a great commercial centre named VIALIA, with an extension of approximately $100,000 \mathrm{~m}^{2}$, that contains nine cinemas, restaurants, shops, a bowling centre and a gymnasium with a swimming pool placed between two floors.

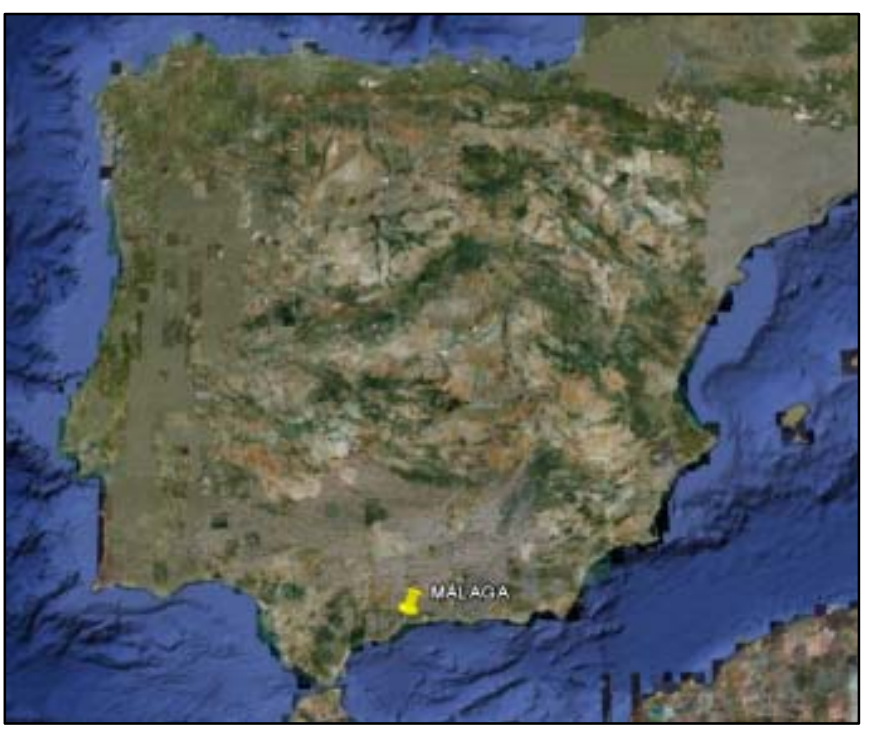

Figure 1. Plant from Madrid to Valladolid connected with the new railway line of high speed
The complex includes a hotel of four stars called Barceló VIALIA, with seven floors and 222 rooms, with dimensions in plant of $48.00 \mathrm{~m}$ for $15.45 \mathrm{~m}$, and with a height over the level of the street of 35.50 $\mathrm{m}$. The Commercial Centre VIALIA includes also a parking with two underground levels whit a surface of $25,000 \mathrm{~m}^{2}$ for 1,300 parking places.

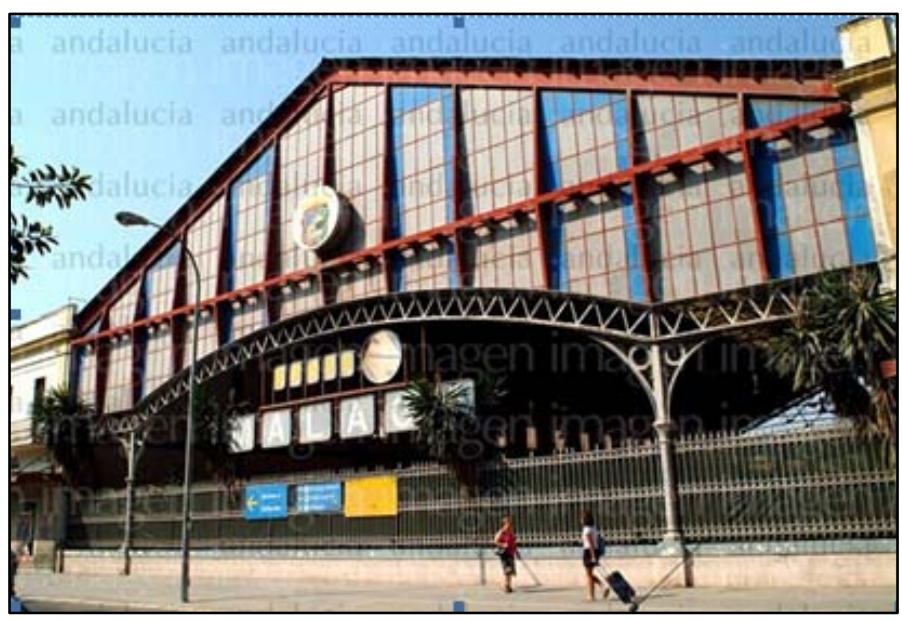

Fig. 2. Former railway station

The new station of AVE (high speed train) of Malaga constitutes the biggest passengers' intermodal and commercial centre of Spain.

The architectural set integrates perfectly the intermodal station that connects the line of AVE, which joins Madrid with Malaga and the suburban rail networks. It comprises a commercial centre named VIALIA, the hotel Barceló VIALIA and an underground parking. 


\section{THE MARQUEE}

Before the trains reach the railway station, it is located a very big marquee with a span of 71 meters without any intermediate pillar. Under the marquee there have been constructed four platforms that give service to 8 trains of high speed called in the Spanish terminology AVE, six with an international width (UIC71) and two with an Iberian width. The pillars of the marquee on both sides, were made in reinforced concrete in the third lower part with a shape of inverted trunk of cone inclined in the three low meters, and fixed in the bottom with two reinforced concrete walls, that will be use as a containment of earths, when it will made the excavations that will be necessary in the future, to lowering the platforms under the level of the surface.

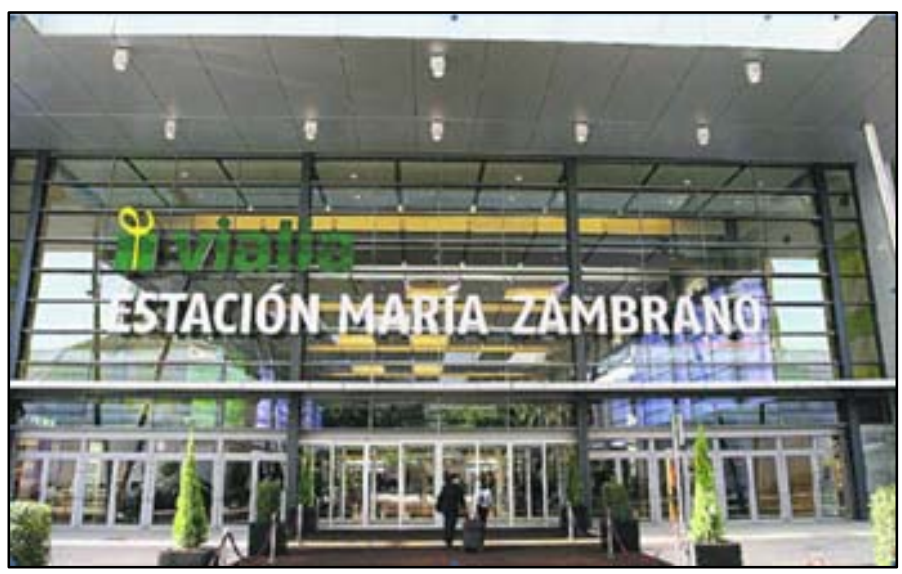

Fig. 3. Entry to the new station of Malaga María Zambrano for high-speed trains.

The roof of the marquee is inclined, with the top part of the pillars in the most elevated one of $16.50 \mathrm{~m}$ of height, joined by means of two tubular profiles of $35.5 \mathrm{~cm}$ of diameter in every support.

The pillars in the less elevated part of the roof have $13.72 \mathrm{~m}$ of height, which makes an appreciable difference of level between both ends of the roof, for the rapid evacuation of the rain water (fig.4).

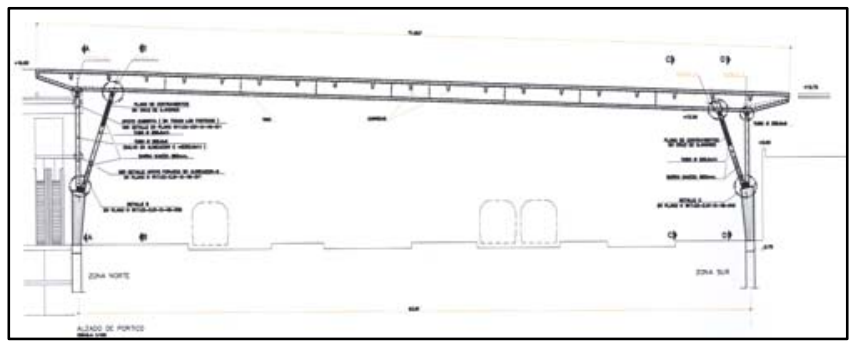

Fig. 4. Transverse section of the marquee

The marquee is tied horizontally on the roof in both ends and vertically in the planes of the tubular pillars with crosses.

The portals of the marquee with different height in his ends of $16.50 \mathrm{~m}$ and $13.72 \mathrm{~m}$ have on the top a girder beam of $1.60 \mathrm{~m}$ of height, with a hollow section in form of trapezium of $60 \mathrm{~cm}$ in the top base and $35 \mathrm{~cm}$ in the bottom one, with the low end rounded with half tubular profile.

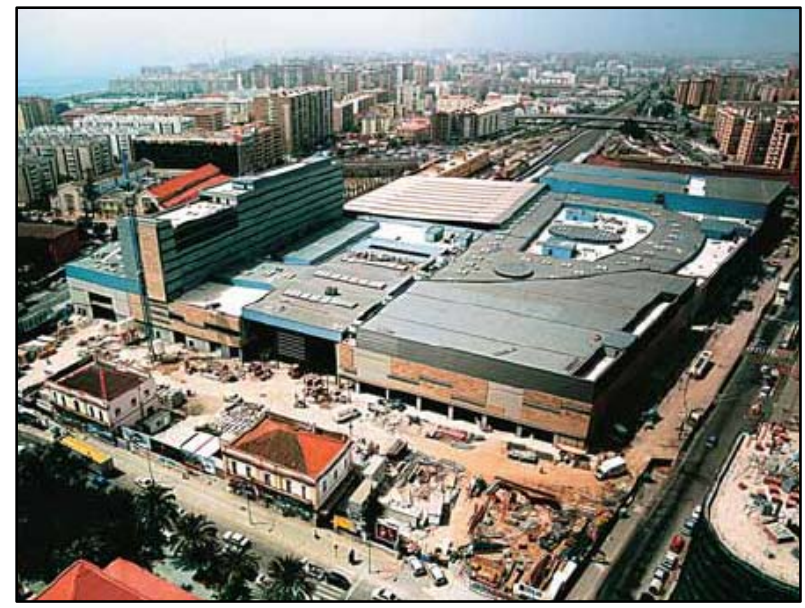

Fig. 5. Air sight of the new railway station

The transverse beams which support the roof of the marquee have a similar section with a high of $60 \mathrm{~cm}$ and a width in the top base of $30 \mathrm{~cm}$. (fig. 6)

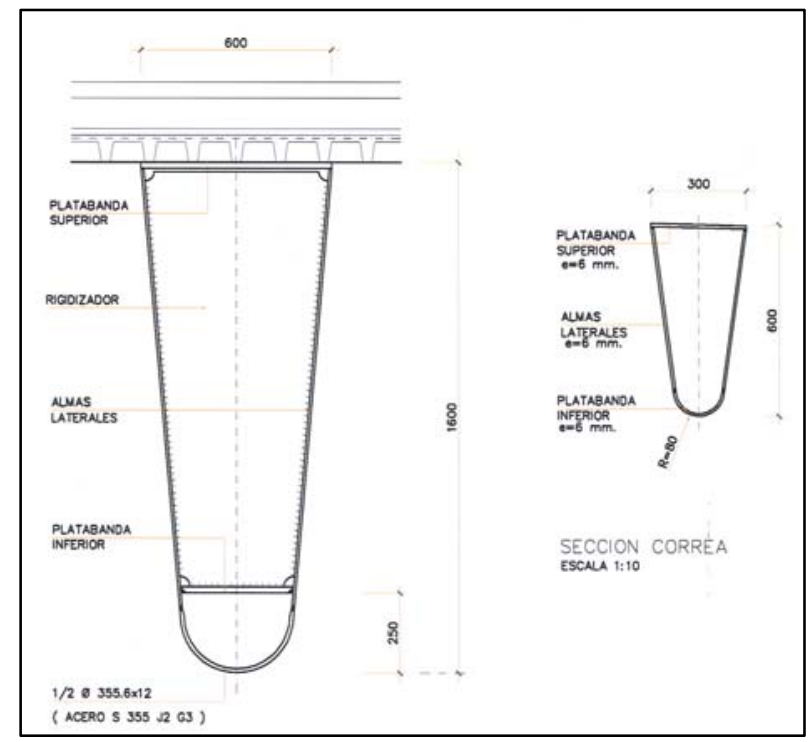

Fig. 6 Transverse section of girders

\section{THE PROJECT}

The Project of the marquee has been realized by means of a model of finite elements realized with the program SAP2000N. The structure is constituted by 10 metallic portals separated $8.00 \mathrm{~m}$ each from the following one, covering a zone of $72.00 \times 71.475 \mathrm{~m}^{2}$. The cover is rigidity by means of San Andres's crossings on initial and end portals of the marquee.

The portal type is constituted by a girder of $1.60 \mathrm{~m}$. of height that covers a span of 63.81 between supports.

The supports of the girder are constituted in every end by two pillars one vertical and the other inclined with the lower part of them in the top of a reinforced concrete pillar tied by two joints together. 


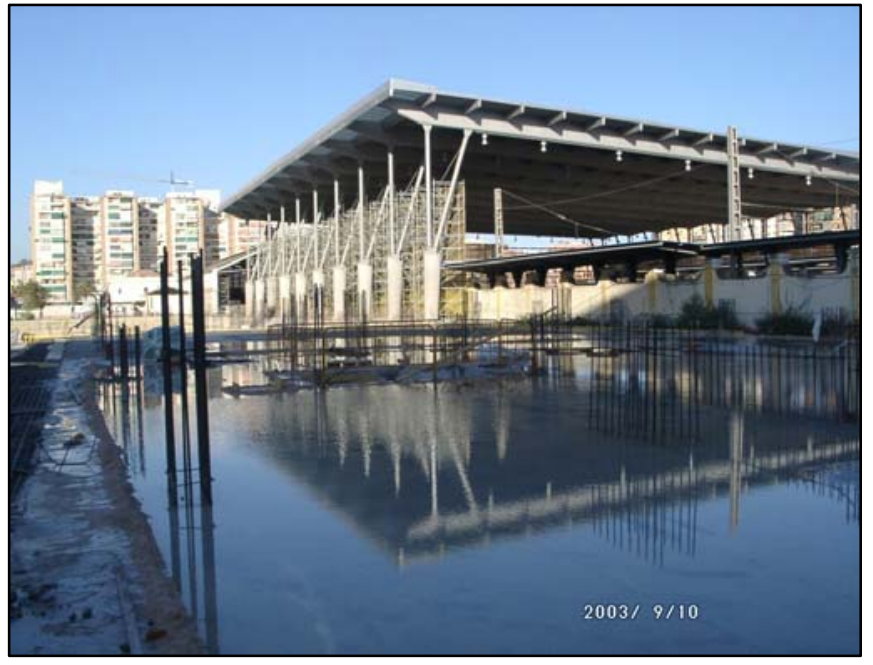

Fig. 7 The marquee from the parking in construction

\section{THE CONSTRUCTION}

The pillars of the marquee begin on the top of a pillar of reinforced concrete over the sheetpiling to support the earth, when in the future the railways will be buried, at their arrival to the station of Málaga, proceeding in that moment to the corresponding excavation.

The pillars of the marquee have a low part of reinforced concrete of $3 \mathrm{~m}$ of height, with a conical section (fig. 8 and 9).

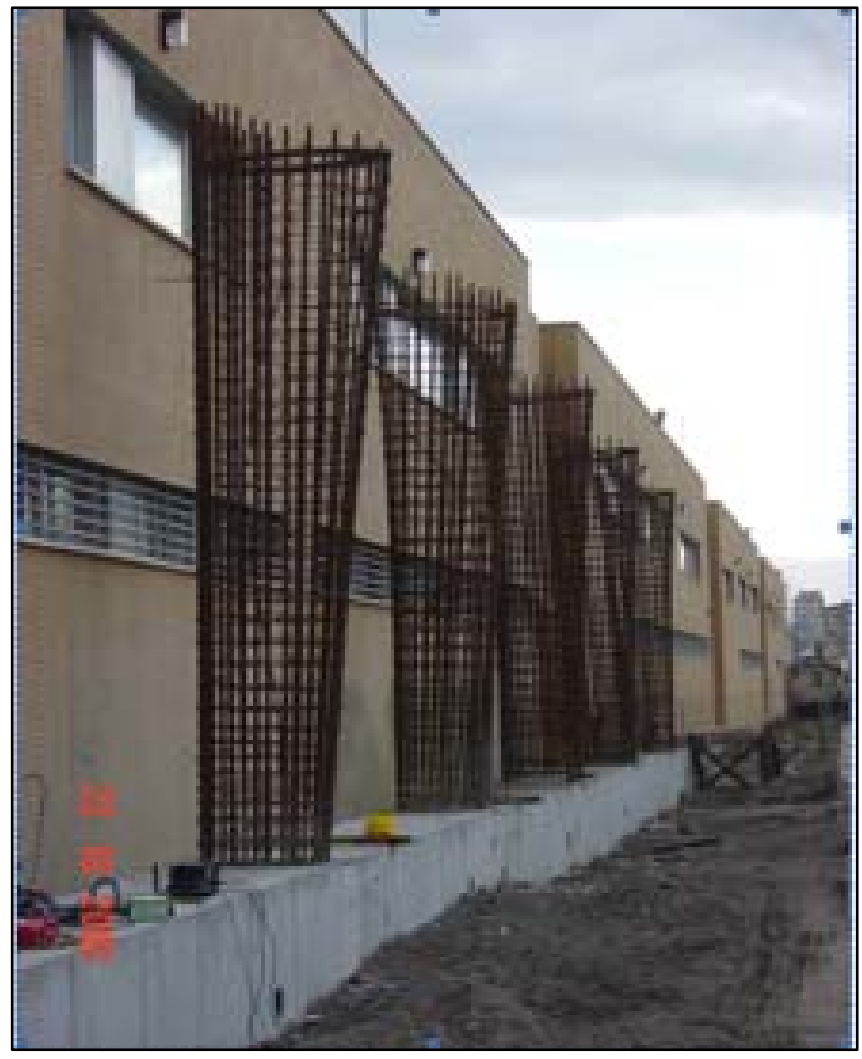

Fig. 8 Supports of reinforced concrete

Over these concrete reinforced supports the metallic pillars of the portals are pinned
The construction of the marquee was realized preassembling in the near area to the station two portals to give him rigidity to the set and raising with derrick to the place where they must be mounted

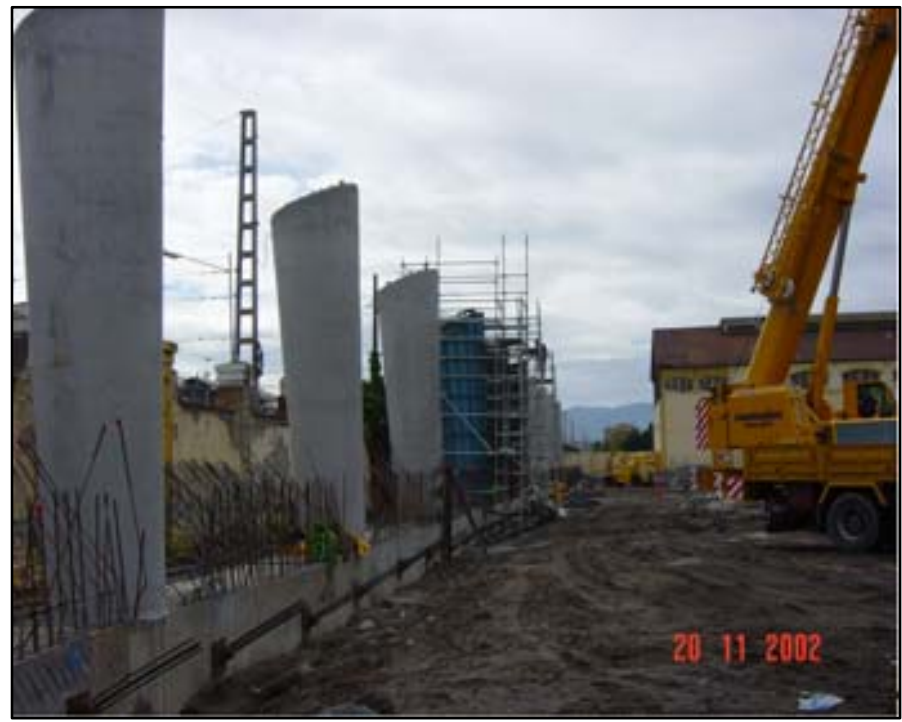

Fig. 9 Supports of reinforced concrete finished

Once mounted the main frame of the marquee and ties a every portal with the others, it was proceeded to place the cover of the marquee, the drainage, the lighting and the rest of finishing

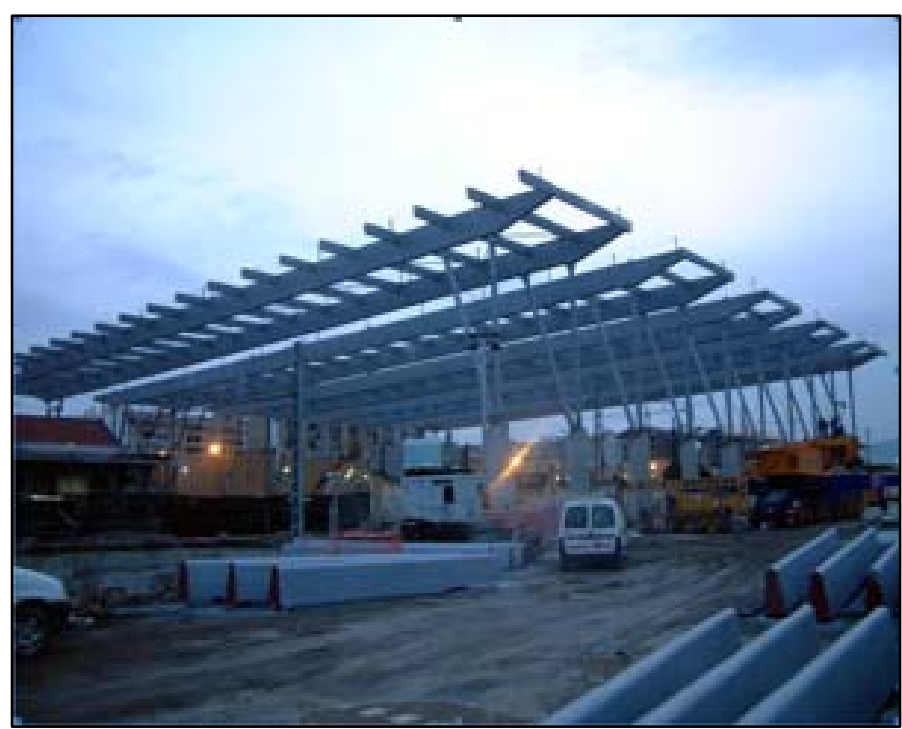

Fig. 10 Construction of the marquee

\section{CONCLUSIONS}

Finally it was constructed the biggest marquee in the railways stations in Spain without any intermediate pillar.

\section{REFERENCES}

- NCSE--O2

- Eurocode 1.1. Bases of project and actions in structures.

- Eurocode 2. Project of structures of reinforced concrete. 
- Eurocode 3. Project of structures of steel.

- Jiménez Salas, Geotecnia y Cimientos. Ed. Rueda.

- Jiménez Montoya, P., García Meseguer, A., Morán Cabré, F. Hormigón armado. 14ª Edition. Ed. Gustavo Gili.

- Ministerio de Fomento. Norm of seismic construction: General part and Building Construction.

- MOPU. Spanish rules relative to the actions to consider in the project of railway bridges. IPF-75

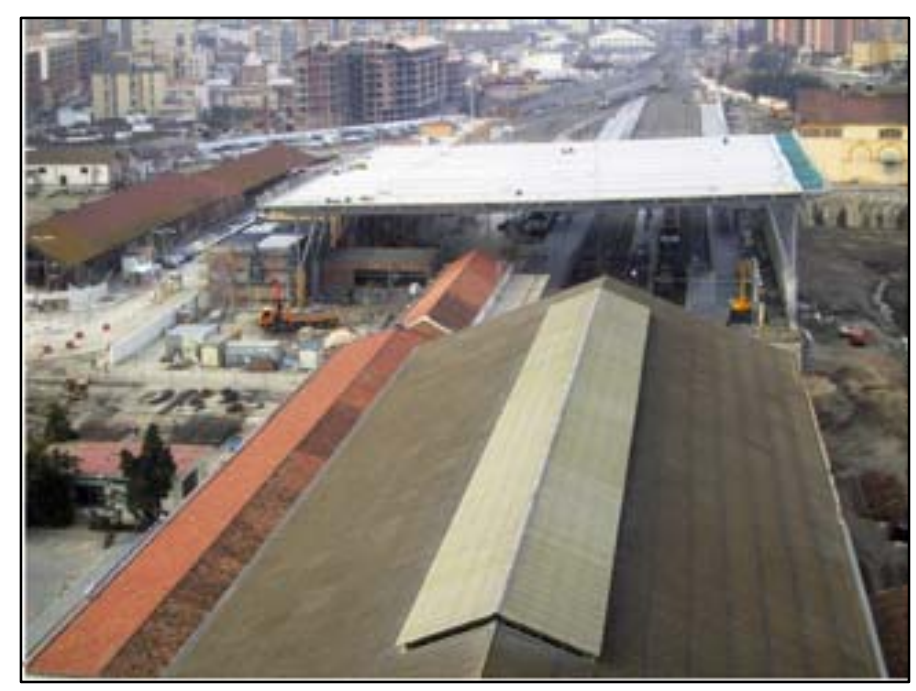

Fig. 11 Air sight of the marquee 